\title{
MATRIZ INSUMO-PRODUTO DE MATO GROSSO 2007: CONSTRUÇÃO E ANÁLISE DOS PRINCIPAIS INDICADORES ECONÔMICOS
}

\author{
Margarida Garcia de Figueiredo ${ }^{1}$ \\ Joaquim José Martins Guilhoto² \\ Sandra Cristina de Moura Bonjour ${ }^{3}$ \\ Euro Roberto Detomini ${ }^{4}$ \\ Adriano Marcos Rodrigues Figueiredo ${ }^{5}$ \\ Karlin Saori Ishii ${ }^{6}$ \\ Wladimir Colman de Azevedo Junior ${ }^{7}$ \\ Sheila Cristina Ferreira Leite ${ }^{8}$ \\ Felipe Deodato da Silva e Silva ${ }^{9}$ \\ Roney Fraga Souza ${ }^{10}$
}

\section{RESUMO}

O estado de Mato Grosso vem apresentando expressivas taxas de crescimento econômico nos últimos anos, de modo que a utilização da matriz insumo-produto, como estratégia de política econômica, representaria não somente a busca da manutenção desse crescimento econômico, mas a preocupação de que o mesmo se traduza em desenvolvimento sócio-econômico. Assim, o presente artigo tem como objetivo geral a apresentação das notas metodológicas de construção da matriz insumo-produto para o Mato Grosso, acompanhadas de uma análise geral da estrutura produtiva da economia do estado. Os principais métodos de análise utilizados no estudo foram os índices de ligações inter-setoriais, bem como os multiplicadores de emprego, renda e produção. Os resultados empíricos confirmaram a importância dos setores primários em termos de suas relações comerciais com as demais atividades, como forma de estimular o aquecimento da economia. Finalmente, através da análise dos multiplicadores, foi possível identificar a importância de diversos setores relacionados ao agronegócio, no que diz respeito às suas capacidades de geração direta e indireta de emprego e renda na economia.

Palavras-chave: Matriz insumo-produto, indicadores econômicos, Mato Grosso.

\section{ABSTRACT}

Thestate of Mato Grosso has been showing remarkable rates of economicgrowth in recent years. Hence, the use of input-output analysis as aeconomic policy strategy would represent not only the search formantaining such economic growth but also the concern that the thisprocess can be converted into socioeconomic development. Thus, thispaper aims to show the general methodological notes for theconstruction of input-output matrix for Matto Grosso followed by anoverview of the State's economy productive structure. The

\footnotetext{
${ }^{1}$ Professora Doutora da Faculdade de Economia da UFMT

${ }^{2}$ Professor Doutor da Universidade de São Paulo USP

${ }^{3}$ Professora Doutora da Faculdade de Economia da UFMT

${ }^{4}$ Professor Doutor da Faculdade de Administração da UNIC.

${ }^{5}$ Professor Doutor da Faculdade de Economia da UFMT

${ }^{6}$ Professora Doutora da Faculdade de Economia da UFMT

${ }^{7}$ Mestrando do Curso de Agronegócios e Desenvolvimento Regional da UFMT

${ }^{8}$ Professora Doutora da Faculdade de Economia da UFMT

${ }^{9}$ Mestrando do Curso de Agronegócios e Desenvolvimento Regional da UFMT

${ }^{10}$ Mestrando do Curso de Agronegócios e Desenvolvimento Regional da UFMT
} 
mainmethods of analysis used in the study were the rates of inter-sectorlinkages and multipliers of employment, income and production. Theempirical results confirmed the importance of primary sectors interms of its trading relations with the other activities as a way tostimulate the growing economy. Finally, through analysis of themultipliers, it was possible to identify the importance of differentsectors related to agribusiness, with regard to their ability togenerate direct and indirect employment and income in the economy.

Key-words: Input-output matrix, economic indicator, Mato Grosso.

\section{INTRODUÇÃO}

0 estado de Mato Grosso possui características interessantes que vêm motivando estudos em vários locais do país e do mundo para se tentar compreender alguns resultados enquanto produção e expansão desta área que, até 1750, pertencia à Espanha, em virtude do Tratado de Tordesilhas (Silva, 1982), e hoje é considerada uma potência agrícola, destacando-se pela produção e exportação de diversos produtos, a exemplo da soja e derivados e da carne bovina.

Sua ocupação territorial foi efetuada aos saltos, com núcleos de povoação surgidos em função de episódios históricos marcantes, como as Bandeiras no séc. XVIII. A mineração atraiu grande contingente populacional para as áreas auriferas que acabaram se transformando em vilas e cidades, até que a região fosse incorporada formalmente ao domínio português em 1750, pelo Tratado de Madri.

Como todo o Centro-Oeste, o estado de Mato Grosso beneficiou-se da política de interiorização do desenvolvimento e integração nacional do período 1940-70. A construção de Brasilia e os incentivos aos grandes projetos agropecuários e de extrativismo, além dos investimentos em infraestrutura, rodovias, hidrelétricas e a ferrovia Novoeste do Brasil, auxiliaram a prosperidade do estado, atraindo grande quantidade de imigrantes entre 1940 e 1970 (Figueiredo, 2003).

Em outubro de 1977 ocorre a divisão do estado de Mato Grosso com a criação de Mato Grosso do Sul. Nessa ocasião, de acordo com dados do censo demográfico do Instituto Brasileiro de Geografia e Estatística - IBGE para 1970, o antigo estado de Mato Grosso tinha cerca de 2.300 .000 habitantes, distribuídos por 93 municípios. Segundo estimativas baseadas no censo de 1970, com o desmembramento, o novo Estado Mato Grosso do Sul, passou a contar com uma população de 1,4 milhão de habitantes, distribuídos em 55 municípios, numa área de cerca de $350.000 \mathrm{~km}^{2}$. Mato Grosso remanescente ficou com uma população de cerca de 900.000 habitantes, distribuídos em $903.357,908 \mathrm{Km}^{2}$, dentro de 38 municípios, que se multiplicaram em decorrência da explosão agrícola.

Atualmente, de acordo com estatísticas do IBGE, o estado de Mato Grosso possui 141 municípios, agrupados em 22 microrregiões político-administrativas, que fazem parte de 5 mesorregiões. A população que era de cerca de 2,5 milhões de pessoas em 2000, passou para cerca de 3 milhões de habitantes em 2010 (Mato Grosso, 2011). 
Mais de 30 anos após a formação de dois estados, o Mato Grosso, que ficou com a região menos rica, apresenta crescimento expressivo. A principal força econômica está no setor agropecuário, com expressiva produção de soja, algodão, milho, arroz e carnes bovina, suína e de aves. Segundo estatísticas do IBGE (2009), Mato Grosso é o maior produtor nacional de soja e algodão, tendo também a maior produtividade quando comparado aos demais estados brasileiros, sendo que para ambos os produtos, a eficiência do sistema de produção faz com que os custos de frete não inviabilizem estas atividades. Além disso, apresenta expressiva safra de milho de inverno (conhecida como safrinha), principalmente associada à rotação de culturas e alimentação animal.

O desenvolvimento da agroindústria dentro do estado, além de trazer novos moradores, fez com que a economia crescesse a um ritmo muito superior à média do país. A indústria da transformação, em especial a alimentícia, é uma das principais atividades da economia mato-grossense. Dois outros destaques seriam para os setores de madeira e álcool, com importância tanto no abastecimento interno quanto no desempenho exportador estadual.

Entretanto, apesar do destaque em termos de crescimento econômico, especialmente do agronegócio, o estado ainda apresenta alguns indicadores sócioeconômicos que necessitam ser melhorados, a exemplo da concentração de renda em algumas regiões, taxa de desemprego, ect. Estas características da economia matogrossense despertam grande interesse por estudos que auxiliem na melhor compreensão do funcionamento de sua estrutura produtiva, bem como da dinâmica das relações entre as atividades econômicas. Em se compreendendo melhor todas estas relações abrem-se possibilidades para elaboração de políticas públicas eficazes no sentido de promover 0 crescimento econômico da região, associado às melhorias nos indicadores sociais, a exemplo de geração e distribuição de emprego e renda.

A matriz insumo-produto, desde sua criação na década de 1930, vem ganhando importância entre os formuladores de políticas públicas e, no decorrer do tempo, transformou-se em poderoso instrumento de planejamento econômico largamente aceito, e num importante guia para os tomadores de decisões em um grande número de países ao redor do mundo. A sua construção e utilização vem crescendo tanto, a ponto de o Novo Sistema de Contas Nacionais de 1993 (SNA-93) recomendar sua utilização integrada a outros instrumentos da contabilidade social.

A única matriz insumo-produto disponível para o Mato Grosso, tem como ano base 0 de 1999, gerando, desta maneira, indicadores desatualizados. O estado vem crescendo e alterando sua estrutura produtiva de maneira significativa após 1999, comprometendo assim, quaisquer prognósticos obtidos a partir da referida matriz. Diante do exposto, justifica-se a construção de uma nova matriz com dados atualizados para as últimas estatísticas disponíveis do Sistema de Contas Regionais (2007), para que os 
formuladores de políticas econômicas de Mato Grosso possam utilizá-la como ferramenta de apoio na tomada de decisões, dentre outras finalidades.

Sendo assim, o presente estudo tem como objetivo principal a construção da matriz insumo-produto para o Estado de Mato Grosso, referente ao ano de 2007, acompanhada de uma análise geral da estrutura produtiva do estado, realizada com base nos principais indicadores econômicos calculados a partir da matriz.

\section{METODOLOGIA}

\subsection{Fontes de dados e procedimentos adotados para a construção da matriz \\ 2.1.1 Construção da MIP Nacional 2007}

O primeiro passo para a construção da matriz insumo-produto inter-regional de Mato Grosso e resto do Brasil, foi a construção da matriz insumo-produto nacional de 2007, a partir das Tabelas de Recursos e Usos (Tabelas 1 e 2) publicadas nas Contas Nacionais do IBGE, referentes ao ano de 2007.

A Tabela 1 das Contas Nacionais equivale à Tabela 1 da matriz insumo-produto, também chamada de Matriz de Produção, trazendo as informações a preços básicos. A Tabela 2 das Contas Nacionais equivale à Tabela 2 da matriz insumo-produto, também chamada de Matriz de Usos, porém, contendo as informações a preços de consumidor. Neste caso, foi necessária a transformação dos valores a preços de consumidor para valores a preços básicos, utilizando a metodologia desenvolvida por Guilhoto e Sesso Filho (2005).

Vale destacar que a classificação das Contas Nacionais 2007 contempla 56 setores (ou atividades produtivas) e 110 produtos. 0 presente estudo manteve a mesma classificação em termos de produtos, no entanto, utilizou uma classificação de 78 setores ao invés de 56, visando atender diversos interesses específicos em termos de estudos e análises futuras. A desagregação dos setores dentro das Tabelas de Recursos e Usos nacionais, bem como a construção destas mesmas tabelas para o estado de Mato Grosso, utilizou diversas fontes de informações, conforme detalhadas a seguir.

O setor " Agricultura, silvicultura, exploração florestal", das Contas Nacionais, foi desagregado em outros 10 setores, a saber: (1) Algodão, (2) Arroz, (3) Cana-de-açúcar, (4) Extrativismo vegetal, (5) Fruticultura, (6) Milho, (7) Produção de madeira, (8) Silvicultura, (9) Soja, e (10) Outras Culturas. Os números na frente de cada setor correspondem às respectivas numerações dentro da classificação utilizada no presente estudo. As desagregações foram feitas utilizando-se informações disponíveis no Banco de Dados Agregados do Sistema IBGE de Recuperação Automática - SIDRA, coletando informações da "Produção Agrícola Municipal" e da "Produção da Extração Vegetal e da Silvicultura", referentes ao ano de 2007. Vale destacar que a Secretaria de Estado de Planejamento e Coordenação Geral - SEPLAN, disponibilizou uma série de planilhas contendo diversas estatísticas dos setores produtivos de Mato Grosso, classificadas segundo a Classificação 
Nacional de Atividades Econômicas - CNAE 1.0. Estas planilhas também continham alguns dados para o Brasil, os quais foram utilizados para complementar as informações na ocasião da desagregação dos setores.

O setor "Pecuária e pesca" foi desagregado em outros seis setores, cujas classificações na pesquisa assumiram os valores de 11 a 16, conforme listados a seguir: (11) Aves, (12) Bovinos (corte), (13) Bovinos (leite), (14) Outros Produção animal, (15) Pesca, e (16) Suínos. Para a desagregação também foram utilizados os dados do SIDRA/IBGE, disponíveis na "Pesquisa Pecuária Municipal", "Pesquisa Trimestral do Leite" e "Pesquisa Trimestral de Abate de Animais". Também foram utilizadas algumas informações das planilhas disponibilizadas pela SEPLAN.

$O$ setor "Alimentos e Bebidas" foi desagregado em outros nove setores, conforme relacionados a seguir: (20) Abate de bovinos, (21) Abate de suínos, (22) Abate de frangos, (23) Abate de outros animais, (24) Indústria de laticínios, (25) Fabricação de açúcar, (26) Fabricação de óleos vegetais, (27) Rações, e (28) Outros produtos alimentares. Para a desagregação foram utilizadas informações das planilhas fornecidas pela SEPLAN; dados do SIDRA/IBGE, referentes a "Pesquisa Trimestral de Abate de Animais"; dados da União da Indústria de Cana-de-Açúcar - UNICA e da Associação Brasileira das Indústrias de Óleos Vegetais - ABIOVE.

No caso dos demais setores, foi mantida a mesma classificação original das Contas Nacionais 2007, de modo que não foi necessária nenhuma desagregação, mantendo-se os mesmos valores disponíveis nas Tabelas de Recursos e Usos (Tabelas $1 \mathrm{e}$ 2) das Contas Nacionais.

\section{0 método de equilíbrio entre oferta e demanda de bens e serviços}

Após a transformação dos valores da Tabela 2 para preços básicos e da desagregação dos setores nas duas tabelas, o próximo passo foi obter o equilíbrio entre oferta e demanda do sistema. Os grupos de produtos dentro de cada setor devem possuir, necessariamente, origem (recurso/oferta) e destino (demanda/uso). Essas relações são definidas nas Tabelas de Recursos e Usos e a identidade básica do Sistema de Contas Nacionais é:

$O$ tratamento das diferenças encontradas entre a oferta e a demanda dos bens e serviços é denominado equilíbrio entre oferta-demanda, sendo realizado para cada um dos setores e produtos que compõem a matriz de insumo-produto. É necessário fazer a confrontação dos valores de oferta e demanda para cada grupo de produtos e serviços, buscando-se zerar as diferenças. 
Os equilíbrios básicos a serem obtidos constituem-se em:

OfertapB $=$ Produção ${ }_{\mathrm{PB}}+$ Importação $_{\mathrm{CIF}}+$ Impostos $^{\text {Imargens }}$

Demanda $_{\mathrm{PB}}=$ Consumo Intermediário + Consumo Final + Formação Bruta de Capital FixOPC + Exportações $_{\mathrm{FOB}}$

em que: $\mathrm{PB}=$ preço básico; $\mathrm{PC}=$ preço ao consumidor; $\mathrm{CIF}=$ preço básico das importações; FOB = preço básico das exportações; Impostos = todos os impostos sobre produtos, serviços e importações; Margens = valores pagos pelos serviços de comércio e transporte, que são incluídos no preço final dos produtos; $\mathrm{e}$,

Consumo Final $=$ inclui o consumo das famílias + consumo da administração pública.

\subsubsection{Construção da Matriz de Produção inter-regional}

O segundo passo para a obtenção do sistema inter-regional foi a construção da Matriz de Produção para o Mato Grosso, que corresponde à Tabela 1 da matriz insumoproduto divulgada pelo IBGE. No que diz respeito aos dados utilizados nesta etapa, estes foram todos disponibilizados pela SEPLAN, oriundos de diversas pesquisas do IBGE para composição das Contas Regionais, a saber: Pesquisa Industrial Anual (PIA), Pesquisa Anual do Comércio (PAC), Pesquisa Anual do Serviço (PAS), Pesquisa Nacional por Amostra de Domicílios (PNAD), Produção Agrícola Municipal (PAM), Pesquisa Pecuária Municipal (PPM), etc. Todas as informações disponibilizadas pela SEPLAN traziam os produtos na classificação CNAE 1.0 , de modo que foi necessária a utilização de um tradutor, ou seja, uma tabela de correspondências para estabelecer a correspondência de todos os produtos inicialmente de CNAE 1.0 para CNAE 2.0. Num segundo momento, compatibilizou-se todas as informações de CNAE 2.0 para a classificação de produtos e setores utilizada nesta pesquisa, associando cada grupo de produtos que são produzidos por cada um dos setores considerados no estudo, até fechar a Matriz de Produção de Mato Grosso.

Posteriormente, subtraiu-se esta Matriz de Mato Grosso da Matriz de Produção Nacional, obtendo-se assim a Matriz de Produção do Resto do Brasil. Com isso foi possível montar o sistema inter-regional correspondente à Matriz de Produção Mato Grosso X Resto do Brasil.

\subsubsection{Construção da Matriz de Usos inter-regional}

A matriz de usos, correspondente à Tabela 2 da matriz insumo-produto divulgada pelo IBGE, é composta pelo consumo intermediário das atividades, pelos componentes do valor adicionado e pelos componentes da demanda final. 
Desta forma, a construção da matriz de usos inter-regional foi dividida em três etapas: (i) regionalização do consumo intermediário; (ii) regionalização dos componentes da demanda final e (iii) regionalização dos componentes do valor adicionado.

\section{Regionalização dos componentes do consumo intermediário}

O consumo intermediário da matriz inter-regional foi construído aplicando-se a técnica de regionalização do Quociente Locacional Interindustrial no consumo intermediário da matriz de usos nacional. Posteriormente, as estimativas dos coeficientes inter-regionais foram validadas pelos resultados de estudos de caso desenvolvidos especificamente para 0 consumo intermediário das principais atividades econômicas de Mato Grosso.

Segundo Miller e Blair (2009), o Quociente Locacional Interindustrial é dado pela seguinte expressão:

$$
C I Q_{i j}^{R}=\left[\frac{X_{i}^{R} \mathbf{I}}{X_{j}^{R}} \mid \frac{X_{i}^{N}}{X_{j}^{N}}\right]
$$

Em que: $X_{i}^{R}$ é a produção total do setor i na região $\mathrm{R} ; X_{i}^{N}$ é a produção nacional total do setor i; $X_{j}^{R}$ é a produção total do setor $\mathrm{j}$ na região $\mathrm{R} ;$ e $X_{j}^{N}$ é a produção nacional total do setor $\mathrm{j}$.

Esta relação mede a participação do setor regional ofertante no total de produção nacional deste setor em comparação à participação do setor regional demandante em relação ao mesmo setor em termos nacionais.

Se $C I Q_{i j}^{R}$ for menor que 1 , significa que, em decorrência da região $\mathrm{R}$ ter uma produção proporcionalmente menor de produtos do setor i, há uma tendência a se importar este produto. E se for maior ou igual a 1 , os setores que demandam os produtos correspondentes ao setor i não terão necessidade de importá-los. Sendo assim, para a regionalização da matriz de coeficientes técnicos diretos de produção $\left(a_{i j}^{r r}\right)$, utilizou-se o seguinte procedimento:

$$
\{\}
$$

\section{Regionalização dos componentes da demanda final}

Os valores correspondentes aos componentes da demanda final (exportações, formação bruta de capital fixo, gastos do governo e consumo das famílias) foram levantados para o Mato Grosso, a partir de pesquisas específicas, conforme os procedimentos descritos a seguir. Para o Brasil, estes valores foram obtidos diretamente 
das Contas Nacionais 2007, disponibilizadas pelo IBGE. Os valores para o resto do Brasil foram obtidos por diferença. No caso da formação bruta de capital fixo e do consumo das famílias, foi necessário separar, daquilo que era demandado pelo Mato Grosso, o que vinha do próprio estado e o que vinha de fora (do resto do Brasil). Para tanto, utilizou-se a técnica do Quociente Locacional Simples.

De acordo com Miller e Blair (2009), o Quociente Locacional Simples é definido pela relação:

$$
L Q_{i}^{R}=\left\lceil\left[\begin{array}{l|l}
X_{i}^{R} & X^{R} \\
\hdashline X_{i}^{N} & X^{N}
\end{array}\right]\right.
$$

Em que $X_{i}^{R}$ é a produção total do setor i na região $\mathrm{R} ; X^{R}$ é a produção total da região R; $X_{i}^{N}$ é a produção nacional total do setor i; e $X^{N}$ é a produção nacional total.

Para a construção da série de dados de Formação Bruta de Capital Fixo - FBCF para o Mato Grosso, referente ao ano de 2007, não foi possível utilizar os dados desidentificados da Declaração de Informações Econômico-Fiscais da Pessoa Jurídica (DIPJ), uma vez que esses dados não estiveram disponíveis à presente equipe técnica. Desta forma, os números para obter a série de FBCF da administração pública foram obtidos a partir das despesas de investimentos realizados pelas administrações públicas divulgados pela Secretaria do Tesouro Nacional (Ministério da Fazenda) em nível de estados e municípios. Este procedimento é o mesmo do IBGE para as Contas Nacionais e, desta forma, esta informação foi processada similarmente para a MIP de Mato Grosso.

Uma abordagem razoável para estimar a FBCF por produto é primeiro criar uma matriz de FBCF por setores institucionais e por tipos gerais de produtos (residências, edifícios e outras estruturas, equipamentos de transportes, outras máquinas e equipamentos). Em seguida, ampliar os tipos gerais de produtos em produtos mais detalhados usando o método de fluxo de mercadorias (UN, 1999: p.178), descrito em UN (1999: p.183-189).

O consumo final da administração pública são as despesas de consumo final do governo geral, incluindo as despesas dos governos Federal, Estadual e Municipal. Em UN (2000: p.15), este item refere-se ao código P3 das transações do Sistema Internacional de Contas Nacionais das Nações Unidas. Estas despesas são divididas em duas partes: (1) bens e serviços necessários à coletividade; e (2) bens e serviços para necessidades individuais das famílias.

A fonte de informações básicas utilizada nesta pesquisa foram os dados do SIAFI e do FINBRA, para "Despesas Públicas por Funções" (IBGE, 2008), cujos dados referentes ao estado de Mato Grosso, obtidos para o ano de 2007, permitem estimar os gastos com educação, segurança, saúde e outras atividades da administração pública. 
Os valores correspondentes às exportações de Mato Grosso, referentes ao ano de 2007, foram obtidos no sistema Aliceweb do Ministério do Desenvolvimento Indústria e Comércio Exterior - MDIC. Os dados anuais são divulgados em dólares FOB, codificados no sistema Nomenclatura Comum do Mercosul - NCM, para todas as mercadorias. Todos os valores foram transformados para Reais, considerando a taxa de câmbio de $R \$ 1,9483$ por dólar norte-americano.

Desta forma, foi necessário transformar os valores de NCM para Classificação Nacional de Atividades Econômicas - CNAE, feita com base em uma tabela de correspondência de NCM 2007 para CNAE (1.0 e 2.0), com atualização em maio de 2009. Após a transformação dos dados de NCM para CNAE, foi utilizado um tradutor, ou seja, uma tabela de compatibilização entre a classificação CNAE e a classificação desta pesquisa, em 78 setores e 110 produtos.

Os dados para o cálculo do consumo das famílias foram retirados da Pesquisa de Orçamento Familiar - POF de 2008/2009 (IBGE, 2010). Esta pesquisa apresenta 0 consumo das famílias por tipos de produto, em um total de 10.429 produtos na classificação de seis dígitos.

Inicialmente, separou-se somente os dados referentes a Mato Grosso. A seguir realizou-se a compatibilização e agregação entre as categorias presentes na POF e os 78 setores utilizados para a construção da matriz. Após a agregação, utilizou-se um fator de expansão da amostra, para que os dados correspondam a uma estimativa do consumo da população matogrossense.

\section{Regionalização dos componentes do valor adicionado}

Os componentes do valor adicionado na matriz insumo-produto correspondem às importações, impostos (imposto de importação, ICM, IPI e outros impostos indiretos líquidos), remunerações (salários, contribuições sociais efetivas e contribuições sociais fictícias), e excedente operacional bruto. Além disso, considera-se os outros impostos sobre a produção e os outros subsídios à produção. Estes componentes são representados em vinte e cinco linhas que aparecem abaixo do consumo intermediário na matriz de usos.

Os valores totais das importações de Mato Grosso foram obtidas no sistema Aliceweb. Os impostos foram obtidos junto à Secretaria de Estado de Fazenda SEFAZ/MT. As remunerações e o rendimento dos autônomos foram obtidos na Pesquisa Nacional por Amostra de Domicílios - PNAD. 0 excedente operacional bruto foi obtido por resíduo, subtraindo-se do valor bruto da produção, o consumo intermediário, as remunerações e os outros impostos sobre a produção. Todos os valores para o Brasil foram obtidos diretamente nas Contas Nacionais de 2007, e para o resto do Brasil, por diferença entre Brasil e Mato Grosso. 


\subsection{Referencial Teórico}

O modelo teórico utilizado no presente estudo foi inicialmente desenvolvido por Wassily Leontief, em 1930, no qual os fluxos inter-setoriais em uma economia podem ser representados por:

$$
X=A X+Y
$$

onde $\mathrm{X}$ é um vetor (nx1) com os valores da produção total de cada setor, $\mathrm{Y}$ é um vetor (nx1) com os valores da demanda final, e A é uma matriz (nxn) com os coeficientes técnicos de produção (Leontief, 1966). Neste modelo, o vetor da demanda final pode ser considerado como exógeno ao sistema, então o nível total de produção pode ser determinado pela demanda final, da seguinte forma:

$$
\begin{gathered}
X=B Y \\
B=(I-A)^{-1}
\end{gathered}
$$

Sendo $B$ uma matriz $(n \times n)$ conhecida como Inversa de Leontief.

Pela equação (08) é possível estimar o impacto da demanda final na produção total e, a partir daí, no emprego e salário. Além disso, a partir da matriz Inversa de Leontief são calculados uma série de indicadores econômicos, os quais permitem analisar cuidadosamente as principais relações dentro da estrutura produtiva de um país.

Embora este modelo seja originariamente elaborado para estudos das relações internas da economia de uma nação, o interesse pela análise econômica em âmbito regional induziu modificações nos modelos visando adaptá-los às investigações de determinadas regiões e suas relações com as demais. Desta forma, os indicadores podem ser calculados tanto para uma nação como um todo quanto para suas regiões em particular. Alguns estudos regionais que fizeram uso de modelos de insumo-produto referem-se aos trabalhos de Guilhoto e Ichihara (2006), Guilhoto et al (2006), Haddad et (2002), Caballero e Kureski (2003), Sesso Filho et al (2006), Porsse et al (2008). Referencias internacionais são Isard (1951), Moses (1955), Hewings (1984), Lahr (1993) e artigos da edição especial da Regional Studies (2010) - Innovations in Regional Computable General Equilibrium (CGE) Modelling.

Quanto aos indicadores econômicos para a análise da estrutura produtiva de Mato Grosso, foram calculados os Índices de Rasmussen-Hirschman, os Índices Puros de Ligações Normalizados e os Multiplicadores de Emprego, Renda e Produção, conforme descritos a seguir.

\section{Índices de Rasmussen-Hirschman}

Para o cálculo desses índices define-se como sendo um elemento da matriz inversa de Leontief $B ; B^{*}$ como sendo a média de todos os elementos de $B$; e e

como sendo, respectivamente, a soma de uma coluna e de uma linha típica de $B$, e as expressões do índice de ligações para trás (poder de dispersão) 


$$
U_{j}=\left[B^{*} \backslash n\right] \mid B^{*}
$$

e dos índices de ligações para frente

$$
U_{j}=\left[B_{i} \Downarrow n\right] \mid B^{*}
$$

(sensibilidade da dispersão)

\section{Índices Puros de Ligações}

Baseado em Guilhoto et al. (1996), o cálculo dos índices puros de ligações parte da decomposição de uma matriz $\mathrm{A}$, que contém os coeficientes de insumos diretos do setor destacado j e o resto da economia:

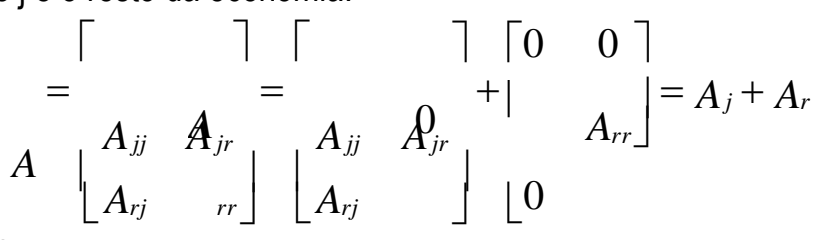

Os componentes e são, respectivamente, matrizes que representam insumos diretos do setor $j$ e do resto da economia; e representam matrizes dos insumos diretos comprados pelo setor $j$ do resto da economia e os insumos diretos comprados pelo resto da economia do setor $j$. A matriz representa o setor $j$ isolado do resto da economia e a matriz representa o resto da economia.

Partindo da equação acima chega-se a:

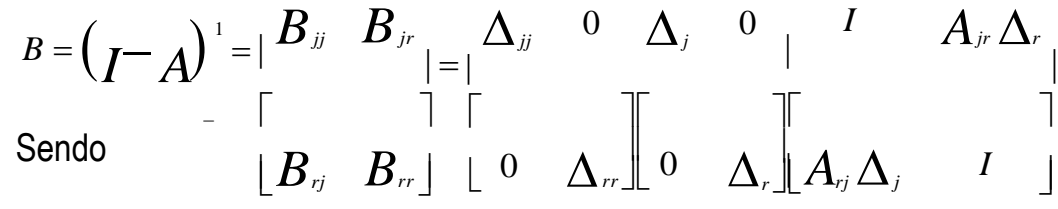

$$
\begin{aligned}
& \Delta_{j}=\left(I-A_{j j}\right)^{-1} \\
& \Delta_{r}=\left(I-A_{r r}\right)^{-1} \\
& \Delta_{i j}=\left(I-\Delta_{j} A_{j r} \Delta_{r} A_{r j}\right)^{-1} \\
& \Delta_{r r}=\left(I-\Delta_{r} A_{r j} \Delta_{j} A_{j r}\right)^{-1}
\end{aligned}
$$
dadas por:

As novas definições para os índices de ligações para trás e para frente serão

$$
\begin{aligned}
& P B L=\Delta_{r} A_{r j} \Delta_{j} Y_{j} \\
& P F L=\Delta_{j} A_{j r} \Delta_{r} Y_{r}
\end{aligned}
$$

○ $P B L$ indicará o impacto puro sobre o resto da economia do valor da produção total na região j. Impacto puro porque, segundo Guilhoto et al (1996), ele está livre: (a) da demanda de insumos que a região j produz para a região j; (b) dos retornos do resto da 
economia para a região j e vice versa. Por sua vez, o $P F L$ indicará o impacto puro sobre a região j, do valor da produção total no resto da economia r.

0 índice puro total de ligações ( $P T L$ ) de cada setor na economia é obtido adicionando-se o $P B L$ ao $P F L$, visto que estes índices são expressos em valores correntes.

$$
P T L=P B L+P F L
$$

\section{Multiplicadores de produção}

Denotando os elementos da matriz $B=(I-A)^{-1}$ por $b_{i j}$, temos o multiplicador tipo l:

$$
M P_{j}=\sum_{i=1}^{n} b_{i j}
$$

onde $j$ representa um determinado setor da economia.

Para o multiplicador tipo II, calcula-se a matriz inversa de Leontief $\bar{B}=(I-\bar{A})^{-1}$, cujos coeficientes são $\bar{b}_{i j}$, e é obtida a partir de uma matriz $\bar{A}$ de coeficientes técnicos, onde o consumo das famílias é endogeneizado.

$$
M \bar{P}_{j}=\sum_{i=1}^{n} \bar{b}_{i j}
$$

\section{Multiplicadores de emprego}

O multiplicador de emprego para um determinado setor j é dado por:

$$
\left.M E_{j}=\sum_{i=1}^{n}\left(w_{n+1, i} b_{i j}\right)\right) w_{n+1, j}
$$

No qual:

$W_{n+1}$ é o número de empregos gerados por unidade monetária produzida

$b_{i j}$ representa os elementos da Inversa de Leontief.

\section{Multiplicadores de renda}

Algebricamente, tem-se o multiplicador:

$$
M R_{j}=\sum_{i=1}^{n}\left(a_{n+1, i} b_{i j}\right) a_{n+1, j}
$$

Sendo:

$a_{n+1, i}$ corresponde aos elementos da linha dos coeficientes de remuneração das famílias. $b_{i j}$ representa os elementos da inversa de Leontief. 


\section{RESULTADOS E DISCUSSÃO}

Os principais resultados da pesquisa são constituídos pelos índices de ligações intersetoriais (Índices de Rasmussen-Hirschman e Índices Puros de Ligações Normalizados) e pelos multiplicadores de emprego, renda e produção.

\section{1. Índices de ligações de Rasmussen-Hirschman}

É conveniente recordar que os índices de ligações para trás indicam o que cada setor demanda dos demais (poder de dispersão), enquanto os índices para frente mostram o quanto cada setor é demandado pelos demais (sensibilidade da dispersão). Vale relembrar que existem dois critérios básicos para a determinação dos setores-chave para o crescimento de uma economia. O primeiro, proposto por Rasmussen-Hirschman, classifica como setores-chave aqueles que apresentam pelo menos um dos índices de ligação, para frente ou para trás, acima de um. O segundo critério, proposto por McGilvray (1977), considera um setor como chave se esse apresentar ambos os índices, para frente e para trás maiores do que um, simultaneamente.

Com relação às ligações para trás, apontando a importância dos setores como demandantes da produção dos demais, trinta e oito atividades econômicas destacaram-se com valores maiores do que um, ou seja, acima da média em comparação com as outras. Dentre estes setores, dezessete estão diretamente relacionados ao agronegócio, importante atividade econômica no estado. É bastante forte a presença dos setores relacionados com cadeias agroindustriais de produtos animais, como bovinos, aves e suínos. Entretanto, alguns setores de base, como (46) Cimento e (48) Fabricação de aço e derivados, também têm forte presença na economia, reforçando a importância destas indústrias enquanto compradores de produtos e serviços dos demais setores.

Quanto às ligações para frente, apontando a importância dos setores como ofertantes de produção na economia, trinta e sete atividades apresentaram valores maiores do que um, destacando-se entre elas dezenove setores diretamente relacionados ao agronegócio, corroborando a importância destas atividades em dinamizar a economia matrogrossense. Vale ressaltar que, entre estes principais fornecedores de matéria-prima ao consumo intermediário estão os setores (9) Soja e (12) Bovinos de corte, ocupando a vigésima sétima e a trigésima sétima posições no rank, respectivamente, em virtude das vendas para as esmagadoras de soja e para os frigoríficos, duas das principais atividades econômicas de Mato Grosso.

Na recomendação de McGilvray (1977), vinte e dois setores seriam identificados como chave na economia matogrossense. Estas atividades destacaram-se ao dinamizar a economia tanto pela demanda quanto pela oferta e, portanto, merecem atenção especial por parte dos formuladores de políticas públicas, visando promover 0 crescimento econômico da região. Para melhor visualização destes resultados, a Tabela 1 mostra apenas os setores que se destacaram por apresentar índices de ligações, para trás e para 
frente, maiores do que um, respectivamente. Observa-se que oito destes setores estão diretamente relacionados ao agronegócio, destacando-se entre eles o setor (13) Bovinos de leite, que é uma atividade pouco expressiva no estado, entretanto, apresenta potencial de contribuir positivamente ao crescimento econômico de Mato Grosso, e seria interessante prestar mais atenção nas políticas voltadas ao desenvolvimento desta atividade. Outros destaques, que também merecem a atenção dos formuladores de políticas públicas seriam (27) Rações, (33) Produtos de madeira, exclusive móveis, (30) Têxteis e (37) Álcool.

Tabela 1 - Índices de R-H dos setores de Mato Grosso identificados como chave por apresentarem tanto ligações para trás quanto ligações para frente maiores do que um - sistema todo.

\begin{tabular}{clcc}
\hline N. setor & \multicolumn{1}{c}{ Setor } & Trás & Frente \\
\hline 13 & Bovinos (leite) & 1,01 & 1,34 \\
19 & Outros da indústria extrativa & 1,19 & 1,48 \\
26 & Fabricação de óleos vegetais & 1,39 & 1,29 \\
27 & Rações & 1,41 & 1,30 \\
30 & Têxteis & 1,08 & 1,17 \\
33 & Produtos de madeira - exclusive móveis & 1,14 & 1,23 \\
34 & Celulose e produtos de papel & 1,17 & 3,23 \\
35 & Jornais, revistas, discos & 1,00 & 1,28 \\
37 & Álcool & 1,09 & 1,15 \\
38 & Produtos químicos & 1,18 & 1,66 \\
39 & Fabricação de resina e elastômeros & 1,16 & 1,59 \\
41 & Defensivos agrícolas & 1,28 & 1,54 \\
43 & Tintas, vernizes, esmaltes e lacas & 1,17 & 1,16 \\
44 & Produtos e preparados químicos diversos & 1,12 & 1,52 \\
45 & Artigos de borracha e plástico & 1,14 & 1,45 \\
46 & Cimento & 1,18 & 1,30 \\
47 & Outros produtos de minerais não-metálicos & 1,10 & 1,19 \\
49 & Metalurgia de metais não-ferrosos & 1,11 & 1,11 \\
50 & Produtos de metal - exclusive máq. e eq. & 1,09 & 1,23 \\
54 & Máquinas, aparelhos e materiais elétricos & 1,10 & 1,19 \\
59 & Peças e aces. para veículos automotores & 1,21 & 1,26 \\
65 & Logística & 1,02 & 1,15 \\
\hline
\end{tabular}

Fonte: Resultados da pesquisa

Outro setor que chama atenção por suas fortes ligações é o (34) Celulose e produtos de papel. Embora seja uma atividade também pouco expressiva no estado, os indicadores apontam que ela tem potencial em promover o crescimento econômico de Mato Grosso, dinamizando as relações comerciais através de suas compras e vendas. Isto 
sugere que seria interessante para os formuladores de políticas públicas para desenvolvimento, prestarem mais atenção também neste setor. 0 interessante em se analisar índices de ligações que não levam em consideração o valor bruto da produção das atividades, é que eles permitem identificar setores que são pouco expressivos na economia, porém, têm potencial de contribuir ao crescimento econômico, dinamizando a economia através de suas ligações de compra e venda, a exemplo de bovinos de leite e celulose e papel.

Entretanto, justamente pelo fato de os índices de Rasmussen-Hirschman não levarem em consideração o valor bruto da produção total das indústrias, apontando apenas o grau de ligação entre elas, sua análise deve ser complementada pelos índices puros de ligações normalizados, os quais levam em consideração o valor da produção de cada setor.

\section{2. Índices puros de ligações normalizados}

Estes índices também medem o grau de ligação entre as atividades econômicas, comprando e vendendo produtos, levando em consideração o tamanho de cada atividade dentro da estrutura produtiva. Merece destaque 0 setor (26) Fabricação de óleos vegetais, que ocupa posição importante entre os setores-chave. Sua produção impacta a produção dos demais setores em 6,71 vezes acima da média (comprando insumos), e é impactada pelo restante da economia em 1,26 vezes acima da média (vendendo sua produção). Diretamente relacionado à esta atividade está o setor (9) Soja, cuja produção é demandada pelas atividades econômicas em 6,24 vezes acima da média, um bom indicativo da importância que tem o setor em termos de aquecimento da economia do estado, vendendo sua produção para ser utilizada como insumo.

O setor (20) Abate de bovinos, quando comparado com os outros, ocupa a primeira posição no ranking dos setores-chave, sendo o que mais impacta a produção do resto da economia através de suas compras, em 13,13 vezes acima da média. Isto está relacionado a sua grande demanda pela produção do setor (12) Bovinos de corte, o que se justifica pelo fato de Mato Grosso ser o principal estado brasileiro produtor e exportador de carne vermelha, considerando ainda que o Brasil ocupa a primeira posição no rank mundial de exportação de carne vermelha (FAO, 2010). A pecuária bovina, embora de uns anos para cá tenha perdido espaço para a agricultura no Mato Grosso, especialmente para a soja, continua se constituindo um importante setor para a economia do estado, o que pode ser confirmado pela terceira posição no ranking dos setores-chave, ocupada pelo setor (12) Bovinos de corte. Este setor, embora não apresente demanda significativa sobre a produção da economia como um todo, tem sua produção demandada pelo resto da economia em 10,20 vezes acima da média, ocupando a primeira posição no ranking de ligações para frente, como vendedor de matéria-prima. O fato da atividade (12) Bovinos de corte não se destacar como importante demandante na economia pode ser, em parte, explicado pela caratcerística do sistema de produção no estado, que é mais extensiva. 
Apesar de a pecuária intensiva estar ganhando espaço em Mato Grosso, ainda há forte predomínio da atividade extensiva, devido ao baixo risco da atividade.

Valores dos índices puros de ligações totais normalizados acima de um, identificam os setores considerados como chave ou pólos de desenvolvimento econômico em uma região, porque suas produções impactam a produção do resto da economia, e ao mesmo tempo são impactadas pela mesma, em uma proporção acima da média dentre os demais setores pertencentes à mesma região. A Tabela 2 permite melhor visualização dos vinte e dois setores de Mato Grosso que se destacaram como chave ou pólos de desenvolvimento econômico do estado, de acordo com os índices puros de ligações totais normalizados.

Vale ressaltar que nove destes setores estão diretamente relacionados à agropecuária, sendo que cinco destes pertencem às atividades primárias, corroborando a importância da agropecuária dentro da estrutura produtiva econômica de Mato Grosso, em termos de suas relações comerciais com as demais atividades. Merecem atenção os setores (20) Abate de Bovinos, (12) Bovinos de corte, (26) Fabricação de óleos vegetais e (9) Soja, ocupando posições de destaque no ranking, reforçando a importância econômica destas atividades para o estado.

Nota-se que o setor (78) Administração pública e seguridade social, ocupa a quarta posição no ranking, dinamizando a economia principalmente em função de sua demanda, representando importante comprador das atividades econômicas de Mato Grosso. Além disso, diversas atividades pertencentes ao setor terciário, de serviços, destacaram-se como pólos de desenvolvimento econômico de Mato Grosso, sinalizando a importância de se investir nestas atividades como forma de promover o desenvolvimento econômico do estado. Merecem destaque os setores (63) Construção e (68) Serviços imobiliários e aluguel, que se destacaram entre os setores-chave, corroborando a importância do mercado imobiliário de Mato Grosso, o qual vem crescendo significativamente nos últimos anos.

\subsection{Multiplicadores}

0 modelo insumo-produto permite mensurar o efeito de uma mudança exógena na demanda final de um determinado setor sobre o número de pessoas ocupadas, o nível de renda gerada (em termos salariais) e a produção total gerada na economia, através dos multiplicadores tipos I e II, de emprego, renda e produção, respectivamente. 0 multiplicador de emprego tipo I mostra os impactos diretos e indiretos, ou seja, permite auferir quantos empregos são gerados na economia, direta e indiretamente, devido a uma variação na demanda final de uma determinada indústria, o suficiente para criar um emprego adicional na mesma. De forma análoga, os multiplicadores tipo I de renda e produção permitem a determinação da quantidade de renda e da produção total, geradas na economia em decorrência de uma unidade monetária adicional de renda (salário líquido) e produção 
gerados em cada setor, respectivamente. A idéia do multiplicador tipo II é conceitualmente a mesma, diferindo-se, entretanto, pela endogeneização do consumo das famílias, produzindo assim os efeitos diretos, indiretos e induzidos.

No entanto, para melhor avaliar a capacidade de geração de empregos e renda de cada indústria, deve-se determinar, além dos multiplicadores, os geradores de emprego e renda. Ao atender a demanda final de um determinado setor da economia em um milhão de Reais, os geradores de empregos diretos, indiretos e induzidos trazem o número de pessoas ocupadas diretamente no setor, indiretamente nos demais setores e aqueles empregos gerados pelo efeito induzido pelo consumo das famílias endogeneizado, respectivamente. De forma análoga, os geradores de renda diretos, indiretos e induzidos trazem a quantidade total de renda gerada na economia de forma direta, indireta e induzida. A soma dos três indicadores representa a geração total de emprego e renda, respectivamente, ao atender a demanda final de cada setor em um milhão de Reais.

Tabela 2 - Índices puros de ligações totais normalizados para o Mato Grosso.

\begin{tabular}{clcc}
\hline N. setor & \multicolumn{1}{c}{ Setor } & Índice & Ordem \\
\hline 20 & Abate de bovinos & 6,82 & 1 \\
64 & Comércio & 5,91 & 2 \\
12 & Bovinos (corte) & 5,58 & 3 \\
78 & Administração púb. e seguridade social & 4,09 & 4 \\
26 & Fabricação de óleos vegetais & 3,99 & 5 \\
63 & Construção & 3,63 & 6 \\
9 & Soja & 3,54 & 7 \\
65 & Logística & 3,38 & 8 \\
67 & Intermediação financeira & 2,99 & 9 \\
66 & Serviços de informação & 2,85 & 10 \\
28 & Outros produtos alimentares & 2,80 & 11 \\
62 & S.I.U.P. & 2,51 & 12 \\
10 & Outras Culturas & 2,09 & 13 \\
71 & Serviços prestados às empresas & 2,07 & 14 \\
70 & Serviços de alojamento e alimentação & 1,91 & 15 \\
38 & Produtos químicos & 1,60 & 16 \\
74 & Serviços prestados às famílias & 1,56 & 17 \\
3 & Cana-de-açúcar & 1,33 & 18 \\
68 & Serviços imobiliários e aluguel & 1,30 & 19 \\
25 & Fabricação de açúcar & 1,27 & 20 \\
73 & Saúde mercantil & 1,19 & 21 \\
76 & Educação pública & 1,15 & 22 \\
\hline
\end{tabular}

Fonte: dados da pesquisa. 


\subsubsection{Efeito multiplicador do emprego}

A Tabela 3 mostra os valores encontrados para as dez primeiras posições no rank da economia mato-grossense, em termos de efeito multiplicador de empregos. Tomando como exemplo o setor (26) Fabricação de óleos vegetais, para cada emprego gerado diretamente na atividade, são gerados 90,48 empregos adicionais na economia, e ao se considerar o efeito induzido pelo consumo das famílias, este valor sobe para 291,77 empregos, ou seja, 201,28 empregos adicionais são decorrentes deste efeito. Como esta indústria apresenta elevado padrão de automatização relativamente às indústrias presentes no Estado, ou seja, é relativamente intensiva em capital, gera um grande volume de produção por pessoa empregada, o que justifica a grande quantidade de empregos gerados no restante da economia para cada emprego adicional gerado na mesma, colocando-a na primeira posição em relação às demais atividades de Mato Grosso, em termos de capacidade de multiplicação de empregos.

Outros setores pertencentes à cadeia do agronegócio da economia matogrossense, pelos mesmos motivos descritos anteriormente, destacam-se também como importantes multiplicadores de emprego, a saber: (25) Fabricação de açúcar, (41) Defensivos Agrícolas, (37) Álcool, (20) Abate de bovinos, (21) Abate de suínos, (22) e Abate de frangos. Em outras palavras, estas atividades apresentam elevada produtividade do trabalho, empregando poucas pessoas diretamente para geração de grande volume de produção e, consequentemente, com elevada capacidade de multiplicação do emprego na economia.

Tabela 3 - Multiplicadores de emprego para o Mato Grosso.

\begin{tabular}{llcccc}
\hline \multicolumn{1}{c}{ Setor } & Tipo I & Ordem & Tipo II & Ordem \\
\hline 26 & Fabricação de óleos vegetais & 91,48 & 1 & 292,77 & 1 \\
49 & Metalurgia de metais não-ferrosos & 30,51 & 2 & 219,13 & 2 \\
25 & Fabricação de açúcar & 26,95 & 3 & 48,97 & 10 \\
46 & Cimento & 25,22 & 4 & 123,95 & 4 \\
39 & Fabricação de resina e elastômeros & 20,67 & 5 & 137,24 & 3 \\
48 & Fabricação de aço e derivados & 15,13 & 6 & 93,43 & 5 \\
41 & Defensivos agrícolas & 14,99 & 7 & 60,12 & 7 \\
38 & Produtos químicos & 14,64 & 8 & 80,54 & 6 \\
37 & Álcool & 14,49 & 9 & 24,79 & 16 \\
59 & Peças e aces. para veículos automot. & 9,11 & 10 & 54,90 & 8 \\
20 & Abate de bovinos & 8,94 & 11 & 18,40 & 19 \\
21 & Abate de suínos & 8,82 & 12 & 19,07 & 18 \\
\hline
\end{tabular}

Fonte: Resultados da pesquisa

Além disso, merecem destaque alguns setores da indústria de base, tais como:

(49) Metalurgia de metais não ferrosos, (46) Cimento e (48) Fabricação de aço e derivados; 
por se destacarem ocupando posições importantes no ranking das principais atividades com capacidade de multiplicação do emprego na economia. Isto sugere que maiores investimentos nestes setores podem contribuir significativamente ao desenvolvimento econômico do estado.

Vale ressaltar que, os setores que apresentam baixa capacidade de multiplicação do emprego na economia, por apresentarem baixa produtividade do trabalho, se destacam pela elevada capacidade de geração direta de postos de trabalho. Tais atividades empregam maior número de pessoas diretamente, para gerar a produção necessária para atender sua demanda final, conforme exposto nos resultados da Tabela 4.

O setor (15) Pesca, por exemplo, gera 977,8 empregos diretos ao atender sua demanda final em $\mathrm{R} \$ 1$ milhão, colocando-o na primeira posição no ranking em termos de capacidade de garação direta de empregos. A segunda posição no ranking fica para o setor (75) Serviços domésticos, gerando 347,3 empregos diretos ao atender sua demanda final. Este é um setor tipicamente intensivo em mão-de-obra, caracterizado pela baixa produtividade do trabalho, ocupando grande quantidade de pessoas diretamente.

Nota-se que diversos setores primários apresentam esta característica de elevada capacidade de geração direta de empregos. Isto sugere a importância de se investir nestas atividades, pois além de exercerem forte influência na economia do estado em termos de participação no PIB, também contribuem positivamente para a geração de empregos diretos em Mato Grosso.

Tabela 4 - Geração de empregos diretos, indiretos e induzidos, para a variação de $R \$ 1$ milhão na demanda final do setor.

\begin{tabular}{llccccc}
\hline \multicolumn{1}{c}{ Setor } & Total & Ordem & Diretos & Indiretos & Induzidos \\
\hline 15 & Pesca & 1.084 & 1 & 977,8 & 20,1 & 85,6 \\
75 & Serviços domésticos & 456 & 2 & 347,6 & 0 & 108,6 \\
5 & Fruticultura & 429 & 3 & 328,3 & 8,9 & 92,1 \\
3 & Cana-de-açúcar & 303 & 4 & 204,7 & 10,1 & 88 \\
1 & Algodão & 206 & 5 & 117,7 & 12,8 & 75,3 \\
2 & Arroz & 204 & 6 & 98,6 & 18,4 & 87,2 \\
70 & Serviços de aloj. e aliment. & 195 & 7 & 73,9 & 27,3 & 93,5 \\
37 & Álcool & 192 & 8 & 7,8 & 104,7 & 79,8 \\
25 & Fabricação de açúcar & 177 & 9 & 3,6 & 93,8 & 79,6 \\
11 & Aves & 169 & 10 & 60 & 26,8 & 82,4 \\
10 & Outras Culturas & 168 & 11 & 77,8 & 17,7 & 72,7 \\
13 & Bovinos (leite) & 167 & 12 & 66,1 & 19,1 & 81,8 \\
\hline
\end{tabular}

Fonte: Resultados da pesquisa 


\subsubsection{Efeito multiplicador da renda}

Os resultados para os multiplicadores de renda apresentados na Tabela 5 são interpretados da seguinte forma: o multiplicador tipo I do setor (26) Fabricação de óleos vegetais, indica que são gerados $R \$ 42,58$ de renda (salário líquido) na economia como um todo, de forma direta e indireta, para cada um Real de renda gerada diretamente na própria atividade. A interpretação dos valores para o multiplicador tipo II é parecida, porém, indica que para cada um Real de renda gerada no próprio setor, são gerados $\mathrm{R} \$ 96,97$ de renda na economia como um todo, considerando-se os efeitos diretos, indiretos e induzidos. Note que este setor é responsável por um elevado efeito multiplicador de renda na economia, colocando-o na primeira posição do ranking em termos de capacidade de multiplicação da renda, uma característica intrínseca de setores intensivos em capital, com elevada produtividade do trabalho.

Merecem destaque alguns setores diretamente relacionados a cadeia da pecuária, importante atividade econômica em Mato Grosso, a saber: (21) Abate de suínos, (20) Abate de bovinos e (22) Abate de frangos, ocupando as $3^{\mathrm{a}}$, $4^{\mathrm{a}}$ e $6^{\mathrm{a}}$ posições no ranking, respectivamente.

Outros setores são também identificados como importantes multiplicadores de renda na economia, a exemplo de (28) Outros produtos alimentares, (25) Fabricação de açúcar, (27) Rações, (37) Álcool, (41) Defensivos agrícolas e (24) Indústria de laticínios. Observa-se que boa parte das atividades que se destacam nesta característica, estão diretamente relacionadas ao agronegócio, corroborando mais uma vez a importância da cadeia na estrutura produtiva do estado, também no que diz respeito à elevada capacidade de multiplicação de renda na economia.

Tabela 5 - Multiplicadores de renda para o Mato Grosso.

\begin{tabular}{llcccc}
\hline \multicolumn{1}{c}{ Setor } & Tipo I & Ordem & Tipo II & Ordem \\
\hline 26 & Fabricação de óleos vegetais & 42,58 & 1 & 96,97 & 1 \\
28 & Outros produtos alimentares & 36,65 & 2 & 79,71 & 2 \\
21 & Abate de suínos & 28,43 & 3 & 56,2 & 3 \\
20 & Abate de bovinos & 19,29 & 4 & 39,94 & 5 \\
25 & Fabricação de açúcar & 18,66 & 5 & 44,72 & 4 \\
22 & Abate de frangos & 14,63 & 6 & 27,68 & 6 \\
27 & Rações & 9,97 & 7 & 23,21 & 8 \\
46 & Cimento & 6,64 & 8 & 19,49 & 9 \\
37 & Álcool & 5,9 & 9 & 13,77 & 12 \\
41 & Defensivos agrícolas & 5,38 & 10 & 15,85 & 10 \\
24 & Indústria de laticínios & 5,13 & 11 & 10,91 & 14 \\
61 & Móveis e prod. das indústrias diversas & 4,57 & 12 & 15,32 & 11 \\
\hline
\end{tabular}

Fonte: Resultados da pesquisa 
A capacidade de geração de renda, em valores absolutos, depende da quantidade de pessoas ocupadas e do nível dos salários pagos pelo próprio setor e daqueles diretamente relacionados à ele. Os dados referentes à geração de renda para a variação de um milhão de Reais da demanda final, são apresentados na Tabela 6 . Nota-se que alguns setores primários (agricultura) têm elevada capacidade de geração direta de renda quando comparados aos demais, porém, também apresentam elevada capacidade de geração direta de empregos. Isto sugere que são atividades que pagam relativamente baixos salários aos seus empregados, apesar de empregarem elevado número de pessoas diretamente. Um setor que se destaca nesta característica é o da (15) Pesca, ocupando a oitava posição no ranking em termos de geração direta de renda e a primeira posição em termos de geração de emprego, ou seja, emprega muita gente com baixos salários. No caso do setor (6) Milho, que ocupa a vigésima quarta posição em termos de capacidade de geração direta de emprego e a nona posição em termos de capacidade de geração direta de renda, os números sugerem que é um setor que emprega menos pessoas, porém, com salários melhores.

Os setores responsáveis pelas maiores gerações de renda direta na economia matogrossense encontram-se entre os terciários (serviços), a saber: (75) Serviços domésticos, (76) Educação pública, (69) Serviços de manutenção e reparação, (77) Saúde pública e (72) Educação mercantil. Dentre estes, apenas o setor (75) Serviços domésticos encontrou-se entre os principais geradores de emprego, uma vez que se trata de um setor que emprega muita gente à baixos salários, e os demais, possivelmente são setores que empregam relativamente poucas pessoas com maiores salários.

Tabela 6 - Geração de renda direta, indireta e induzida, ao atender a demanda final do setor em R $\$ 1$ milhão.

\begin{tabular}{llccccc}
\hline \multicolumn{1}{c}{ Setor } & Total & Ordem & Direta & Indireta & Induzida \\
\hline 75 & Serviços domésticos & 1,59 & 1 & 0,88 & 0 & 0,71 \\
76 & Educação pública & 1,36 & 2 & 0,64 & 0,07 & 0,64 \\
69 & Serviços de man. e rep. & 1,23 & 3 & 0,59 & 0,06 & 0,58 \\
15 & Pesca & 1,22 & 4 & 0,48 & 0,16 & 0,57 \\
77 & Saúde pública & 1,21 & 5 & 0,49 & 0,12 & 0,6 \\
5 & Fruticultura & 1,21 & 6 & 0,55 & 0,05 & 0,6 \\
3 & Cana-de-açúcar & 1,2 & 7 & 0,52 & 0,09 & 0,59 \\
72 & Educação mercantil & 1,2 & 8 & 0,49 & 0,13 & 0,59 \\
16 & Suínos & 1,17 & 9 & 0,45 & 0,16 & 0,56 \\
13 & Bovinos (leite) & 1,16 & 10 & 0,44 & 0,17 & 0,56 \\
4 & Extrativismo vegetal & 1,16 & 11 & 0,41 & 0,12 & 0,63 \\
70 & Serviços de alojamento e alimentação & 1,16 & 12 & 0,38 & 0,15 & 0,62 \\
\hline
\end{tabular}

Fonte: Resultados da pesquisa 


\subsubsection{Efeito multiplicador da produção}

Os resultados para os multiplicadores de produção apresentados na Tabela 7 são interpretados da seguinte forma: o multiplicador tipo I do setor (28) Outros produtos alimentares indica que são gerados $R \$ 2,75$ de produção na economia como um todo para cada um Real de produção gerada na própria atividade, considerando-se os efeitos diretos e indiretos. A interpretação dos valores para o multiplicador tipo II é a mesma, porém, este indica que para cada um Real de produção gerada no setor, são gerados $\mathrm{R} \$ 5,12$ de produção na economia como um todo, considerando-se os efeitos diretos, indiretos e induzidos. Os setores com valores maiores que 2,00 indicam efeitos mais que proporcionais na economia, ou seja, para cada unidade monetária gerada no próprio setor, são geradas mais do que uma unidade monetária no restante da economia.

Dentre os setores produtivos de Mato Grosso, aqueles com maior efeito multiplicador de produção encontram-se no setor secundário, como por exemplo, (28) Outros produtos alimentares, (22) Abate de frangos, (27) Rações, (21) Abate de suínos, (26) Fabricação de óleos vegetais, (20) Abate de bovinos, (32) Artefatos de couro e calçados, (24) Indústria de laticínios, (41) Defensivos agrícolas e (25) Fabricação de açúcar, todos pertencentes à cadeia do agronegócio. Isto mais uma vez contribui para ressaltar a importância da cadeia do agronogócio na economia matogrossense.

Tabela 7 - Multiplicadores de produção para o Mato Grosso.

\begin{tabular}{llcccc}
\hline \multicolumn{1}{c}{ Setor } & Tipo I & Ordem & Tipo II & Ordem \\
\hline 28 & Outros produtos alimentares & 2,75 & 1 & 5,12 & 3 \\
22 & Abate de frangos & 2,72 & 2 & 4,96 & 11 \\
27 & Rações & 2,59 & 3 & 4,99 & 7 \\
21 & Abate de suínos & 2,59 & 4 & 4,97 & 10 \\
26 & Fabricação de óleos vegetais & 2,55 & 5 & 4,83 & 21 \\
20 & Abate de bovinos & 2,49 & 6 & 4,87 & 15 \\
32 & Artefatos de couro e calçados & 2,36 & 7 & 4,93 & 12 \\
24 & Indústria de laticínios & 2,36 & 8 & 4,89 & 13 \\
41 & Defensivos agrícolas & 2,35 & 9 & 5,01 & 6 \\
25 & Fabricação de açúcar & 2,25 & 10 & 5,03 & 5 \\
59 & Peças e aces. para veículos automot. & 2,22 & 11 & 4,86 & 18 \\
19 & Outros da indústria extrativa & 2,19 & 12 & 4,57 & 39 \\
\hline
\end{tabular}

Fonte: Resultados da pesquisa

\section{CONCLUSÕES}

Este trabalho objetivou avaliar a importância relativa das principais atividades econômicas na estrututura produtiva de Mato Grosso, um estado que vem apresentando 
considerável crescimento econômico desde a década de 70 , em especial no caso dos setores relacionados ao agronegócio.

Da teoria econômica sabe-se que, à medida que uma economia se desenvolve, usualmente uma porção cada vez menor do PIB provém da agricultura, e um contingente cada vez menor da força de trabalho depende diretamente das atividades primárias, o que não implica em redução da importância do setor, e sim conduz à mudança de ênfase quanto aos papéis da agricultura no crescimento econômico. Os resultados empíricos confirmaram a importância dos setores primários em termos de suas relações comerciais com as demais atividades, como forma de estimular o aquecimento da economia, bem como a importância dos produtos agrícolas no mercado internacional, como forma de atrair ganhos cambiais ao país, além de impactar positivamente a produção de diversos outros setores na economia.

Os resultados empíricos do estudo também corroboram a importância das cadeias do agronegócio para a economia do estado. Diversos setores diretamente relacionados à estas atividades foram identificados como pólos de desenvolvimento econômico, através de suas relações de compra e venda na economia. Além disso, estes setores demonstaram desempenhar importante papel no que diz respeito à capacidade de geração direta e indireta de emprego e renda, especialmente em Mato Grosso, mas também em outros estados brasileiros.

Ainda, verificou-se que alguns setores terciários, de prestação de serviços, destacaram-se como importantes atividades com elevada capacidade de geração de renda na economia. Isto sugere que a criação de políticas que estimulem investimentos nestas atividades contribuiria positivamente ao desenvolvimento econômico do estado.

Finalmente, é importante mencionar que, embora os resultados do trabalho tenham sido considerados satisfatórios ao atender os objetivos propostos pela pesquisa, a principal dificuldade enfrentada para a construção desta matriz inter-regional foi quanto à disponibilidade de dados, especialmente os regionais. Assim, ressalta-se a necessidade da divulgação de indicadores regionalizados e pesquisas setoriais em periodicidade maior, principalmente associadas à formação de capital fixo e a balança comercial interestadual. Isso contribuiria positivamente para a elaboração de futuras matrizes inter-regionais e intersetoriais.

\section{REFERÊNCIAS BIBLIOGRAFICAS}

CABALLERO, B. , KURESKI, R. Contabilidade Social para a economia do Paraná, 2000: Tabelas básicas de insumo-produção. In: II ECOPAR., 2, 2003, Maringá. Anais... Maringá: UEM-UEL-UEPGUNIOESTE-IPARDES, 2003, p. 241-259.

FAO. Statistical databases: Faostat: agriculture. http://www.fao.org. (01 Mar. 2010) 
FIGUEIREDO, M.G. Agricultura e estrutura produtiva do Estado do Mato Grosso: uma análise insumo-produto. Piracicaba, 2003. 205p. Dissertação (Mestrado) - Escola Superior de Agricultura "Luiz de Queiroz", Universidade de São Paulo.

GUILHOTO, J. J. M. ; ICHIHARA, S. M. . PIB do Agronegócio Baiano, 2004. Bahia Agrícola, Bahia, v. 7, n. 2, p. 29-37, 2006.

GUILHOTO, J. J. M. ; MORETTO, A. C. ; RODRIGUES, R. L. ; SESSO FILHO, U. A. Interações sinérgicas e transbordamento do efeito multiplicador de produção das grandes regiões do Brasil. Revista de Economia Aplicada, v. 10, p. 225-247, 2006.

GUILHOTO, J.J.M.; SESSO FILHO, U.A. Estimação da matriz insumo-produto a partir de dados preliminares das Contas Nacionais. Economia Aplicada, v.9, n.1, p.1-23, abr-jun. 2005.

GUILHOTO, J.J.M.; SONIS, M.; HEWINGS, G.J.D. Linkages and multipliers in a multiregional framework: integrations of alternative approaches. Illinois: REAL, 1996. 19p. (Discussion Paper, 8)

HADDAD, E. A. AZZONI, C.R.; DOMINGUES, E.P.; PEROBELLI, F.S. Macroeconomia dos estados e matriz interestadual de insumo-produto. Economia aplicada, v.6, n.4, 2002, p.875-895.

HEWINGS, Geoffrey J.D. The role of prior information in updating regional input-output models. Socio-Economic Planning Sciences, Volume 18, Issue 5, 1984, Pages 319-336.

Instituto Brasileiro de Geografia e Estatística - IBGE. Produção agrícola municipal. Rio de Janeiro, 2009. http://www.sidra.ibge.gov.br/bda (02 jun. 2010)

Instituto Brasileiro de Geografia e Estatística - IBGE. Pesquisa de Orçamentos Familiares. Rio de Janeiro, 2009. http://www.sidra.ibge.gov.br/bda (02 ago. 2010)

Instituto Brasileiro de Geografia e Estatística - IBGE. Sistema de Contas Nacionais: Brasil. 2. ed. Rio de Janeiro : IBGE, 2008. 172p. (Relatórios metodológicos v. 24).

Instituto Brasileiro de Geografia e Estatística - IBGE. Contas Regionais do Brasil. 2003-2007. Rio de Janeiro : IBGE, 2009. 90p. (Relatórios metodológicos v. 28).

ISARD, Walter. Interregional and Regional Input-Output Analysis: A Model of a Space-Economy. The Review of Economics and Statistics, v. 33, n.4, Nov. 1951, p. 318-328.

LAHR, M.L. A Review of the Literature Supporting the Hybrid Approach to Constructing Regional Input-Output Models. Economic Systems Research. Volume 5, Issue 3, 1993, Pages 277 - 293.

LEONTIEF, W. The structure of american economy, 1919-1939. New York: Oxford University Press, 1966. 264p. 
MATO GROSSO. SEPLAN. Anuário Estatístico de Mato Grosso - 2008. Vol. 30./ Secretaria de Estado de Planejamento e Coordenação Geral. - Cuiabá : SEPLAN-MT / Carlini \& Caniato, 2009. $672 \mathrm{p}$.

MCGILVRAY, J. Linkages, key sectors and development strategy. In: LEONTIEF, W. Structure, system and economic policy. Cambridge: University Press, 1977. p.49-56.

MILLER, R.E.; BLAIR, P.D. Input-ouput analysis: foundations and extensions. New York: Cambridge University Press, 2009. 745p.

MOSES, Leon N. The Stability of Interregional Trading Patterns and Input-Output Analysis. The American Economic Review, v.45, Dec, n.5, 1955. p. 803-826.

PORSSE, A.A.; PEIXOTO, F.C.; PALERMO, P.U. Matriz de Insumo-Produto inter-regional Rio Grande do Sul-Restante do Brasil 2003: metodologia e resultados. Porto Alegre: FEE, 2008. 25p. (Texto para Discussão, 38)

REGIONAL STUDIES, Volume 44, Issue 10, 2010, Pages 1307 - 1310.

SESSO FILHO, U.A.; MORETTO, A.C. ; RODRIGUES, R.L. ; GUILHOTO, J.J.M.

Interações sinérgicas e transbordamento do efeito multiplicador de produção das grandes regiões do Brasil. Economia Aplicada, v. 10, n.2, Abril-Jun. 2006, p. 225-247.

SILVA, A.C.S. Mato Grosso permanece grande e forte: a economia mato-grossense após a divisão. Goiânia: Única, 1982. 210p.

UN - UNITED NATIONS. Handbook of input-output table compilation and analysis. Studies in Methods: Handbook of National Accounting, Series F, n. 74. New York: UN, 1999. 